\title{
Prevalence of gastrointestinal symptoms and related drug use among pregnant women of South-Western Nigeria
}

\author{
Abiodun Christopher Jemilohun ${ }^{1}$, Adeniyi Olanipekun Fasanu ${ }^{2}$, Aramide Mikhail Tijani ${ }^{3}$, \\ Olayinka Gbenga Stanley ${ }^{1}$
}

\begin{abstract}
${ }^{1}$ Department of Medicine, Gastroenterology Unit, Ladoke Akintola University of Technology Teaching Hospital, Ogbomoso, Oyo State, Nigeria

${ }^{2}$ Department of Obstetrics \& Gynaecology, Ladoke Akintola University of Technology Teaching Hospital, Osogbo, Osun State, Nigeria

${ }^{3}$ Department of Obstetrics, Gynaecology \& Perinatology, Ladoke Akintola University of Technology Teaching Hospital, Ogbomoso, Oyo State, Nigeria
\end{abstract}

Received: 18 August 2015

Accepted: 29 August 2015

\section{*Correspondence:}

Dr. Abiodun Christopher Jemilohun,

E-mail: chrislohun2010@hotmail.com

Copyright: ( ) the author(s), publisher and licensee Medip Academy. This is an open-access article distributed under the terms of the Creative Commons Attribution Non-Commercial License, which permits unrestricted non-commercial use, distribution, and reproduction in any medium, provided the original work is properly cited.

\section{ABSTRACT}

Background: Gastrointestinal (GI) symptoms are quite common in pregnancy but there is paucity of data in regard to their frequencies in the south-western part of Nigeria. This study was conducted to determine the prevalence of various gastrointestinal symptoms and related drug use among south-western Nigerian women.

Methods: A cross-sectional multicenter study involving three centers in two states of south-western Nigeria from March to August 2014. A composite questionnaire consisting of demographic data, anthropometric indices, obstetrics information, a list of gastrointestinal symptoms and drug usage was administered to 420 consecutive healthy pregnant women at various gestational ages. Data were analysed and presented as means \pm S.D, frequencies and percentages. Relationships between categorical variables were explored with chi-square test. A 5\% significance level $(\mathrm{p}<0.05)$ was considered significant.

Results: Respondents had age range of 18-43years and a mean of $27.26( \pm 4.98)$. The commonest gastrointestinal symptom was nausea $(46.9 \%)$, followed by vomiting $(45.0 \%)$ and then anorexia $(36.2 \%)$. Excessive salivation, heart burn, constipation, regurgitation, and bloating had frequencies of 35.5\%, 28.3\%, 20.7\%, $19.0 \%$ and $18.3 \%$ respectively. Epigastric pain was the least frequent among the symptoms (16.9\%). The association between the parity of respondents and each of the GI symptoms was not statistically significant. But associations between educational status and excessive salivation and anorexia were statistically significant (P-value of 0.018 and 0.023 respectively). Subjects with heartburn had the highest drug usage (23.5\%), followed by those with vomiting (22.8\%). Subjects with excessive salivation $(2 \%)$ had the least drug intake.

Conclusions: Gastrointestinal symptoms are common among pregnant women of south-western Nigeria. There is need for the physician to be abreast with the prevalence of the common pregnancy related GI problems in the particular locality of practice and the appropriate way to manage them.

Keywords: Pregnancy, Gastrointestinal symptoms, Vomiting, Excessive salivation

\section{INTRODUCTION}

Pregnancy is a physiological phenomenon but it is associated with bodily changes that often present with symptoms of diseases which involve nearly all the systems of the body, including the gastrointestinal (GI) system. ${ }^{1}$ Although, most of the disorders experienced during pregnancy are often referred to as 'minor' because they are not life threatening, some of them, like hyperemesis gravidarum, can be life threatening. ${ }^{2,3}$ 
Common GI symptoms with varying prevalence at different stages of pregnancy include- nausea and vomiting occurring in 50-90\% of all patients, excessive salivation (26\%), heartburn and regurgitation (30 to $80 \%$ ), and constipation (11\% to $40 \%$ ) among others. ${ }^{4-11}$ These symptoms are majorly a manifestation of pregnancy associated hormonal alterations which result in anatomical and functional changes in the body of the pregnant woman. ${ }^{10,12-14}$ The changes may cause new symptoms or worsen pre-existing diseases like gastroesophageal reflux disease (GERD) and inflammatory bowel disease. ${ }^{15,16}$

Gastrointestinal symptoms in pregnancy have varying impact on the quality of life of pregnant women depending on the severity and duration of the symptoms; hence, understanding their prevalence and presentation is necessary to optimize care. ${ }^{17-19}$ The prognosis for the mother and child is generally good for most GI disorders associated with pregnancy. ${ }^{10}$ While first trimester vomiting is not generally deleterious to the mother or the foetus, it could impacts negatively on the mother and foetus when prolonged and intractable causing electrolyte abnormalities, acid-base disturbances and weight loss which may require hospitalization (hyperemesis gravidarum). ${ }^{2,3}$

Generally, the severity of symptoms determines the approach to management of patients. Mild symptoms can be managed by reassurance, avoidance of precipitating factors, changes in diet and life style. However, severe and intractable symptoms generally require pharmacotherapy with or without laboratory investigations. ${ }^{10} \mathrm{~A}$ combination of lack of prospective drug trials in pregnancy and physician inexperience makes the choice of medication during pregnancy an anxiety-provoking task. If possible, all medications should be avoided, especially during organogenesis (first 16 weeks), because all medications are potentially harmful to the foetus. The benefits must be adequately weighed against the risk and some treatment can be postponed while patient is being carefully observed until a more appropriate time when the intervention is less risky to the foetus.

This study, which was a multicenter study, sought to determine the prevalence of the common GI symptoms of pregnancy and the various therapeutic measures being taken to ameliorate them among pregnant women of south-western Nigeria origin.

\section{Objectives}

The objectives of the study were to determine the prevalence of various GI symptoms in pregnancy among south-western Nigerian women, to determine the association between some of the symptoms and probable risk factors, and to highlight the various therapeutic measures taken by the women to ameliorate the symptoms.

\section{METHODS}

The cross-sectional study was conducted between March and August 2014. The study population consisted of 420 healthy pregnant women aged 18 and above at various gestational ages attending the antenatal clinics of the LAUTECH Teaching Hospitals Ogbomosho, Oyo State, the LAUTECH Teaching Hospital Oshogbo, Osun State and the Primary Health Center, Oja-Igbo, Ogbomoso, Oyo State.

A composite questionnaire consisting of demographic data, anthropometric indices, obstetrics information, a list of GI symptoms and drug usage was administered to each of the participants after obtaining informed consent. Each participant was asked whether she had experienced each of the GI symptoms since the beginning of gestation till the time the questionnaire was administered. Data were analysed with the Statistical Package for the Social Sciences (SPSS), version 16 (SPSS Inc., Chicago, IL, U.S.A.) and presented as means \pm S.D, frequencies and percentages. Relationships between categorical variables were explored with chi-square test. A 5\% significance level $(\mathrm{p}<0.05)$ was considered significant.

Ethical clearance was obtained from the LAUTECH Teaching Hospital, Ogbomosho Ethical Review committee.

\section{RESULTS}

Table 1 show the demographic and obstetrics characteristics of respondents. Four hundred and twenty pregnant women were interviewed. The age range of respondents was 18-43years and the mean was 27.26 $( \pm 4.98)$. Subjects' parity ranged from $0-5$ with a mean of $1.17( \pm 1.19)$.

Table 1: Age, educational status, parity, and gestational age.

\begin{tabular}{|ll|}
\hline Variables & Frequency $(\mathbf{n}=420)$ \\
\hline$\leq 20$ & \\
\hline $21-30$ & $44(10.5 \%)$ \\
\hline$\geq 31$ & $274(65.2 \%)$ \\
\hline Educational status & $102(24.3 \%)$ \\
\hline Nil/Primary & $55(13.1 \%)$ \\
\hline Secondary & $177(42.1 \%)$ \\
\hline Tertiary & $188(44.8 \%)$ \\
\hline Parity & \\
\hline 0 & $158(37.6 \%)$ \\
\hline 1 & $119(28.3 \%)$ \\
\hline $2-5$ & $143(34.0 \%)$ \\
\hline Current trimester & \\
\hline $1^{\text {st }}$ & $20(4.8 \%)$ \\
\hline $2^{\text {nd }}$ & $147(35.0 \%)$ \\
\hline $3^{\text {rd }}$ & $253(60.2 \%)$ \\
\hline
\end{tabular}


Table 2: Gastrointestinal symptoms.

\begin{tabular}{|lll|}
\hline Frequency $(\mathrm{n}=420)$ & Present & Absent \\
\hline Nausea & $197(46.9 \%)$ & $223(53.1 \%)$ \\
\hline Vomiting & $189(45.0 \%)$ & $231(55 \%)$ \\
\hline Excessive salivation & $149(35.5 \%)$ & $271(64.5 \%)$ \\
\hline Heartburn & $119(28.3 \%)$ & $301(71.7 \%)$ \\
\hline Regurgitation & $80(19.0 \%)$ & $340(81 \%)$ \\
\hline Epigastric pain & $71(16.9 \%)$ & $349(83.1 \%)$ \\
\hline Bloating & $77(18.3 \%)$ & $343(81.7 \%)$ \\
\hline Anorexia & $152(36.2 \%)$ & $268(63.8 \%)$ \\
\hline Constipation & $87(20.7 \%)$ & $333(79.3 \%)$ \\
\hline
\end{tabular}

Of the 420 subjects $37.6 \%$ were nulliparous, $28.3 \%$ were primiparous while $34.0 \%$ were multiparous. Two hundred and seventy four $(65.2 \%)$ subjects were in their third decade of life, $102(24.3 \%)$ were aged $\geq 31$ years while the remainder, $44(10.5 \%)$ were aged $\leq 20$ years. Majority of subjects were in their third trimester $(60.2 \%)$, only $4.8 \%$ were in their first trimester and the remainder $(35.0 \%)$ were in their second trimester. Table 2 shows that the commonest gastrointestinal symptom was nausea (46.9\%) followed by vomiting $(45.0 \%)$ and then anorexia $(36.2 \%)$.

Table 3: Association between parity and GI symptoms.

\begin{tabular}{|c|c|c|c|c|c|}
\hline \multirow[t]{2}{*}{ Symptoms } & & \multicolumn{3}{|c|}{ Parity } & \multirow[b]{2}{*}{ Total } \\
\hline & & 0 & 1 & $2-5$ & \\
\hline \multirow[t]{4}{*}{ Nausea } & Yes & $80(50.6 \%)$ & $59(49.6 \%)$ & $58(40.6 \%)$ & $197(46.9 \%)$ \\
\hline & No & $78(49.4 \%)$ & $60(50.4 \%)$ & $85(59.4 \%)$ & $223(53.1 \%)$ \\
\hline & Total & $158(100 \%)$ & $119(100 \%)$ & $143(100 \%)$ & $420(100 \%)$ \\
\hline & & $X^{2}=3.536$ & $\mathbf{d f}=2$ & $\mathbf{P}=0.171$ & \\
\hline \multirow[t]{4}{*}{ Vomiting } & Yes & $75(47.5 \%)$ & $59(49.6 \%)$ & $55(38.5 \%)$ & $189(45 \%)$ \\
\hline & No & $83(52.5 \%)$ & $60(50.4 \%)$ & $88(61.5 \%$ & $231(55 \%)$ \\
\hline & Total & $158(100 \%)$ & $119(100 \%)$ & $143(100 \%)$ & $420(100 \%)$ \\
\hline & & $X^{2}=3.868$ & $\mathbf{d f}=2$ & $\mathbf{P}=0.145$ & \\
\hline \multirow[t]{4}{*}{ Excessive salivation } & Yes & $55(34.8 \%)$ & $38(31.9 \%)$ & $56(39.2 \%)$ & $149(35.5 \%)$ \\
\hline & No & $103(65.2 \%)$ & $81(68.1 \%)$ & $87(60.8 \%)$ & $271(64.5 \%)$ \\
\hline & Total & $158(100 \%)$ & $119(100 \%)$ & $143(100 \%)$ & $420(100 \%)$ \\
\hline & & $X^{2}=1.532$ & $\mathbf{d f}=2$ & $\mathbf{P}=0.465$ & \\
\hline \multirow[t]{3}{*}{ Heartburn } & Yes & $42(26.6 \%)$ & $41(34.5 \%)$ & $36(25.2 \%)$ & $119(28.3 \%)$ \\
\hline & No & $116(73.4 \%)$ & $78(65.5 \%)$ & $107(74.8 \%)$ & $301(71.7 \%)$ \\
\hline & Total & $\begin{array}{l}158(100 \%) \\
X^{2}=3.136\end{array}$ & $\begin{array}{l}119(100 \%) \\
\mathbf{d f}=2\end{array}$ & $\begin{array}{l}143(100 \%) \\
\mathbf{P}=0.208\end{array}$ & $420(100 \%)$ \\
\hline \multirow[t]{4}{*}{ Regurgitation } & Yes & $39(24.7 \%)$ & $18(15.1 \%)$ & $23(16.1 \%)$ & $80(19 \%)$ \\
\hline & No & $119(75.3 \%)$ & $101(84.9 \%)$ & $120(83.9 \%)$ & $340(81 \%)$ \\
\hline & Total & $158(100 \%)$ & $119(100 \%)$ & $143(100 \%)$ & $420(100 \%)$ \\
\hline & & $X^{2}=5.256$ & $\mathbf{d f}=2$ & $\mathbf{P}=0.072$ & \\
\hline \multirow[t]{4}{*}{ Epigastric pain } & Yes & $29(18.4 \%)$ & $18(15.1 \%)$ & $24(16.8 \%)$ & $71(16.9 \%)$ \\
\hline & No & $129(81.6 \%)$ & $101(84.9 \%)$ & $119(83.2 \%)$ & $349(83.1 \%)$ \\
\hline & Total & $158(100 \%)$ & $119(100 \%)$ & $143(100 \%)$ & $420(100 \%)$ \\
\hline & & $X^{2}=0.506$ & $\mathbf{d f}=2$ & $\mathbf{P}=0.777$ & \\
\hline \multirow[t]{4}{*}{ Bloating } & Yes & $35(22.2 \%)$ & $21(17.6 \%)$ & 21(14.7\%) & $77(18.3 \%)$ \\
\hline & No & $123(77.8 \%)$ & $98(82.4 \%)$ & $122(85.3 \%)$ & $343(81.7 \%)$ \\
\hline & Total & $158(100 \%)$ & $119(100 \%)$ & $143(100 \%)$ & $420(100 \%)$ \\
\hline & & $X^{2}=2.847$ & $\mathbf{d f}=2$ & $\mathbf{P}=0.241$ & \\
\hline \multirow[t]{4}{*}{ Anorexia } & Yes & $58(36.7 \%)$ & $45(37.8 \%)$ & $49(34.3 \%)$ & $152(36.2 \%)$ \\
\hline & No & $100(63.3 \%)$ & $74(62.2 \%)$ & $94(65.7 \%)$ & $268(63.8 \%)$ \\
\hline & Total & $158(100 \%)$ & $119(100 \%)$ & $143(100 \%)$ & $420(100 \%)$ \\
\hline & & $X^{2}=0.384$ & $\mathbf{d f}=2$ & $\mathbf{P}=0.825$ & \\
\hline \multirow[t]{4}{*}{ Constipation } & Yes & $39(24.7 \%)$ & $22(18.2 \%)$ & $26(18.2 \%)$ & $87(20.7 \%)$ \\
\hline & No & $119(75.3 \%)$ & $97(81.5 \%)$ & $117(81.8 \%)$ & $333(79.3 \%)$ \\
\hline & Total & $158(100 \%)$ & $119(100 \%)$ & $143(100 \%)$ & $420(100 \%)$ \\
\hline & & $X^{2}=2.433$ & $\mathbf{d f}=2$ & $\mathbf{P}=0.296$ & \\
\hline
\end{tabular}


Table 4: Association between educational status and GI symptoms.

\begin{tabular}{|c|c|c|c|c|c|}
\hline \multirow{2}{*}{ Symptoms } & & \multicolumn{4}{|c|}{ Educational status } \\
\hline & & Nil/Primary & Secondary & Tertiary & Total \\
\hline \multirow[t]{4}{*}{ Nausea } & Yes & $23(41.8 \%)$ & $76(42.9 \%)$ & $98(52.1 \%)$ & 197(46.9\%) \\
\hline & No & $32(58.2 \%)$ & $101(57.1 \%)$ & $90(47.9 \%)$ & $223(53.1 \%)$ \\
\hline & Total & $55(100 \%)$ & $177(100 \%)$ & $188(100 \%)$ & $420(100 \%)$ \\
\hline & & $X^{2}=3.749$ & $\mathbf{d f}=2$ & $\mathbf{P}=0.153$ & \\
\hline \multirow[t]{4}{*}{ Vomiting } & Yes & $20(36.4 \%)$ & $80(45.2 \%)$ & $89(47.3 \%)$ & $189(45.0 \%)$ \\
\hline & No & $35(63.6 \%)$ & $97(54.8 \%)$ & $99(52.7 \%)$ & $231(55.0 \%)$ \\
\hline & Total & $55(100 \%)$ & $177(100 \%)$ & $188(100 \%)$ & $420(100 \%)$ \\
\hline & & $X^{2}=2.076$ & $\mathbf{d f}=2$ & $\mathbf{P}=0.354$ & \\
\hline \multirow[t]{4}{*}{$\begin{array}{l}\text { Excessive } \\
\text { salivation }\end{array}$} & Yes & $24(43.6 \%)$ & $72(40.7 \%)$ & $53(28.2 \%)$ & $149(35.5 \%)$ \\
\hline & No & $31(56.4 \%)$ & $105(59.3 \%)$ & $135(71.8 \%)$ & $271(64.5 \%)$ \\
\hline & Total & $55(100 \%)$ & $177(100 \%)$ & $188(100 \%)$ & $420(100 \%)$ \\
\hline & & $X^{2}=8.051$ & $\mathbf{d f}=2$ & $\mathbf{P}=0.018$ & \\
\hline \multirow[t]{4}{*}{ Heartburn } & Yes & $15(27.3 \%)$ & $52(29.4 \%)$ & $52(27.7 \%)$ & $119(28.3 \%)$ \\
\hline & No & $40(72.7 \%)$ & $125(70.6 \%)$ & $136(72.3 \%)$ & $301(71.7 \%)$ \\
\hline & Total & $55(100 \%)$ & $177(100 \%)$ & $188(100 \%)$ & $420(100 \%)$ \\
\hline & & $X^{2}=0.168$ & $\mathbf{d f}=2$ & $\mathbf{P}=0.920$ & \\
\hline \multirow[t]{4}{*}{ Regurgitation } & Yes & $14(25.5 \%)$ & $27(15.3 \%)$ & $39(20.7 \%)$ & $80(19 \%)$ \\
\hline & No & $41(74.5 \%)$ & $150(84.7 \%)$ & $149(79.3 \%)$ & $340(81 \%)$ \\
\hline & Total & $55(100 \%)$ & $177(100 \%)$ & $188(100 \%)$ & $420(100 \%)$ \\
\hline & & $X^{2}=3.467$ & $\mathbf{d f}=2$ & $\mathbf{P}=0.177$ & \\
\hline \multirow[t]{4}{*}{ Epigastric pain } & Yes & $11(20 \%)$ & $33(18.6 \%)$ & $27(14.4 \%)$ & 71(16.9\%) \\
\hline & No & $44(80 \%)$ & $144(81.4 \%)$ & $161(85.6 \%)$ & $349(83.1 \%)$ \\
\hline & Total & $55(100 \%)$ & $177(100 \%)$ & $188(100 \%)$ & $420(100 \%)$ \\
\hline & & $X^{2}=1.622$ & $\mathbf{d f}=2$ & $\mathbf{P}=0.444$ & \\
\hline \multirow[t]{4}{*}{ Bloating } & Yes & $5(9.1 \%)$ & $31(17.5 \%)$ & $41(21.8 \%)$ & $77(18.3 \%)$ \\
\hline & No & $50(90.9 \%)$ & $146(82.5 \%)$ & $147(78.2 \%)$ & $343(81.7 \%)$ \\
\hline & Total & $55(100 \%)$ & $177(100 \%)$ & $188(100 \%)$ & $420(100 \%)$ \\
\hline & & $X^{2}=4.734$ & $\mathbf{d f}=2$ & $\mathbf{P}=0.094$ & \\
\hline \multirow[t]{4}{*}{ Anorexia } & Yes & $28(50.9 \%)$ & $66(37.3 \%)$ & $58(30.9 \%)$ & $152(36.2 \%)$ \\
\hline & No & $27(49.1 \%)$ & $111(62.7 \%)$ & $130(69.1 \%)$ & $268(63.8 \%)$ \\
\hline & Total & $55(100 \%)$ & $177(100 \%)$ & $188(100 \%)$ & $420(100 \%)$ \\
\hline & & $X^{2}=7.573$ & $\mathbf{d f}=2$ & $\mathbf{P}=0.023$ & \\
\hline \multirow[t]{4}{*}{ Constipation } & Yes & $12(21.8 \%)$ & $38(21.5 \%)$ & $37(19.7 \%)$ & $87(20.7 \%)$ \\
\hline & No & $43(78.2 \%)$ & $139(78.5 \%)$ & $151(80.3 \%)$ & $333(79.3 \%)$ \\
\hline & Total & $55(100 \%)$ & $177(100 \%)$ & $188(100 \%)$ & $420(100 \%)$ \\
\hline & & $X^{2}=0.224$ & $\mathbf{d f}=2$ & $\mathbf{P}=0.917$ & \\
\hline
\end{tabular}

Excessive salivation, heartburn, constipation, regurgitation, and bloating had frequencies of $35.5 \%$, $28.3 \%, 20.7 \%, 19.0 \%$ and $18.3 \%$ respectively. Epigastric pain was the least frequent among the symptoms (16.9\%). It is important to note that there was a considerable overlap in the symptoms' manifestations.

Respondents' parity had no statistically significant association with any of the GI symptoms (Table3). But respondents' educational status had significant association with excessive salivation and anorexia ( $\mathrm{P}$ value of 0.018 and 0.023 respectively); its association with the other GI symptoms evaluated was however not significant. It was observed that the higher the educational attainment; the lesser the proportion of subjects that had these symptoms (excessive salivation and anorexia). For instance, $43.2 \%, 40.7 \%$ and $28.2 \%$ of respondents with nil/primary, secondary and tertiary education respectively had excessive salivation (Table 4).

Table 5 shows the common drugs used by respondents to treat symptoms, which include promethazine, metoclopramide antacids and vitamin supplements. Majority of subjects with symptoms did not use drugs. Several of the subjects used prescribed drugs they could not identify. 
Subjects with heartburn had the highest drug use $(23.5 \%)$, followed by those with vomiting $(22.8 \%)$. The least drug intake was in subjects with excessive salivation (2\%).

Table 5: GI Symptoms and drug usage.

\begin{tabular}{|lllllllll|}
\hline Symptoms & Drug use & Promet. & Meto. & Unknown & Vit. & Antacid & No drug & Total \\
\hline Nausea & $35(17.8 \%)$ & $10(5.1 \%)$ & $1(0.5 \%)$ & $21(10.7 \%)$ & - & $3(1.5 \%)$ & $162(82.2 \%)$ & 197 \\
\hline Vomiting & $43(22.8 \%)$ & $14(7.4 \%)$ & $1(0.5 \%)$ & $26(13.7 \%)$ & - & $2(1.1 \%)$ & $146(77.2 \%)$ & 189 \\
\hline Excessive salivation & $3(2.0 \%)$ & - & - & $3(2.0 \%)$ & - & - & $146(98.0 \%)$ & 149 \\
\hline Heartburn & $28(23.5 \%)$ & - & - & $2(1.7 \%)$ & - & $26(21.8 \%)$ & $91(76.5 \%)$ & 119 \\
\hline Regurgitation & $7(8.8 \%)$ & - & $1(1.2 \%)$ & $5(6.2 \%)$ & - & $1(1.2 \%)$ & $73(91.2 \%)$ & 80 \\
\hline Epigastric pain & $11(15.5 \%)$ & - & - & $2(2.8 \%)$ & $1(1.4 \%)$ & $8(11.3 \%)$ & $60(84.5 \%)$ & 71 \\
\hline Bloating & $1(2.6 \%)$ & - & - & - & - & $1(1.3 \%)$ & $76(98.7 \%)$ & 77 \\
\hline Anorexia & $12(7.9 \%)$ & - & - & - & $7(4.6 \%)$ & $5(3.3 \%)$ & $140(92.1 \%)$ & 152 \\
\hline Constipation & $2(2.3 \%)$ & - & - & $2(2.3 \%)$ & - & - & $85(97.7 \%)$ & 87 \\
\hline
\end{tabular}

Promet. $=$ Promethazine, Meto. $=$ Metoclopramide, Vit. $=$ Vitamin Supplement, Unknown= Prescribed unknown drugs

\section{DISCUSSION}

Gastrointestinal disorders are some of the commonest complaints by pregnant women. Mostly, they are due to pregnancy hormones induced physiological and anatomical changes in the body of the woman, though they could be an expression of underlying ailment.

In our study, nausea was the commonest GI symptom (46.9\%) and the next was vomiting (45\%). Nausea and vomiting usually occur together in pregnancy, especially during the first trimester, and the condition is often referred to as morning or pregnancy sickness. ${ }^{9,20}$ The values obtained in our study is slightly lower than those obtained in previous studies which set the prevalence of nausea and vomiting to be about 50-90\%.,3,9-11 A study conducted to determine the prevalence of nausea and vomiting of pregnancy (NVP) and its association with race/ethnicity found NVP to be less likely to occur in blacks and Asians $(70.27 \%$ in blacks) than in white/Caucasians $(79.53 \%) .{ }^{11}$ The fact that all the subjects were Black Africans may be responsible for the lower prevalence observed in this study as many of the previously conducted studies in this regard were in the Caucasian population.

Anorexia was the next commonest GI symptom after nausea and vomiting in our study with a prevalence of $36.2 \%$. This is noteworthy because of its negative repercussion on both the foetus and the mother, with only $51 \%$ of pregnancies in anorexic mothers free of complication compared to $75 \%$ in non-anorexic mothers. $^{21}$ Also, maternal underweight in pregnancy which has been associated with anorexia makes the pregnancy high risk. Length at birth of babies of anorexic mothers has also been found to be shorter than that in non-anorexic mothers. ${ }^{22}$
Excessive salivation also called sialorrhea or ptyalism reported in our study with $35.5 \%$ prevalence is believed to occur in pregnant women also suffering from nausea and vomiting. It is also reported mainly by pregnant women in the first trimester, although some still experience it beyond the first trimester. Sialorrhoea in pregnancy is usually not related to any systemic disease. ${ }^{23}$ The pathophysiology is not exactly known. It is believed that it occurs as an accompaniment of nausea during the first trimester as a result of increase in the levels of estrogen and progesterone. ${ }^{23,24}$ Although, this raises the question as to why sialorrhoea is not expressed in as many pregnancies as nausea.

The prevalence of $28.3 \%$ for heartburn in our study is slightly less than the generally reported prevalence of 30 $80 \%$ of pregnant women with the symptom. ${ }^{4,5,15}$ Heartburn and regurgitation often occur concomitantly as the cardinal symptoms of gastroesophageal reflux disease (GERD). Pregnancy related GERD may be as a result of reduced lower esophageal sphincter pressure engendered by increased maternal estrogen and progesterone during pregnancy with estrogen having the priming effect, or as a result of increased intra-abdominal pressure due to gravid uterine enlargement. ${ }^{15}$ The slightly reduced prevalence in our study compared to that of those in the western world is in agreement with a previous study which showed that pregnancy induced heartburn is commoner in Caucasians than in Nigerians. ${ }^{25}$

Constipation has been reported to be the most common of lower gastrointestinal disorders in pregnancy with prevalence between $11-38 \% .^{1,8,26}$ The $20.7 \%$ prevalence of pregnant women with constipation obtained in this study is in agreement, although we did not investigate any other lower GI symptoms for comparison. Dehydration, decreased physical activity, slowed GI transit, pregnancy related hormonal levels alteration (increased progesterone, increased estrogen, decreased 
motilin and increased relaxin), intake of low fiber diet, enlarged gravid uterus, pelvic floor dysfunction and iron supplementation have all been implicated as possible aetiology of constipation in pregnancy. ${ }^{8,26}$

The observed significant association between educational attainment and sialorrhoea/anorexia, though cannot be easily explained, may not be unconnected with the general improvement in sanitation and hygiene practices that often attend higher levels of educational attainment. ${ }^{27}$

The safety of drugs in pregnancy has been categorized by the United States Food and Drug into:

Category A: Adequate, well-controlled studies in pregnant women have not shown an increased risk of fetal abnormalities in any trimester of pregnancy

Category B: Animal studies have revealed no evidence of harm to the fetus; however, there have not been any adequate and well-controlled studies performed in pregnant women. Animal studies have shown an adverse effect, but adequate and well-controlled studies in pregnant women have failed to demonstrate a risk to the fetus in any trimester.

Category $C$ : Animal studies have shown an adverse effect; however, there have not been any adequate and well-controlled studies in pregnant women, or no animal studies have been conducted and there have not been any adequate and well-controlled studies in pregnant women.

Category D: Adequate, well-controlled or observational studies in pregnant women have demonstrated a risk to the fetus. However, the benefits of therapy may outweigh the potential risk. For example, the drug may be acceptable if needed in a life-threatening situation or serious disease for which safer drugs cannot be used or are ineffective

Category $X$ : Adequate, well-controlled or observational studies in animals or pregnant women have demonstrated positive evidence of fetal abnormalities or risks. The use of the product is contraindicated in women who are or may become pregnant. ${ }^{28}$

The common known drugs used by respondents to treat symptoms included promethazine (Category C), metoclopramide (Category B) antacids which often contain magnesium and aluminum (Category $\mathrm{C}$ ) and vitamin supplements are relatively safe in pregnancy. None of the identified drugs belong to category (D and $\mathrm{X})$.

Although, we did not set out to investigate the severity of the gastrointestinal symptoms in this study, the observation that majority of the respondents with symptoms did not take any drug (Table 5) may be an indication that the symptoms such respondents experienced were not severe enough to induce health seeking behavior. It may also be safe to conclude that heartburn is the most discomforting among all the GI symptoms investigated $(23.5 \%)$ since it has the highest percentage of respondents that used drugs. In the treatment of heartburn, modification of lifestyle is first recommended and when symptom persists, antacids, the use of histamine-2 receptors antagonists, upper endoscopy and proton pump inhibitors are recommended, progressively. ${ }^{15}$

Generally, there is need for the physician to be abreast with the prevalence of the common pregnancy related GI problems in the particular locality of practice and the appropriate way to manage them. Lack of knowledge on the part of the physician in this regard can impact negatively on the quality of life of the mother and pregnancy outcome. The physician must be able to distinguish whether these symptoms are those of normal pregnancy or a potentially life-threatening complication such as hyperemesis gravidarum and preeclampsia. The physician must also know which medications are harmless as well as which tests are safe to perform during pregnancy. Often, a team approach is necessary to optimize the care of the pregnant patient with gastrointestinal symptoms.

Funding: No funding sources

Conflict of interest: None declared

Ethical approval: Ethical approval obtained from the

LAUTECH Teaching Hospital, Ogbomosho, Ethical Committee

\section{REFERENCES}

1. Audu BM, Mustapha SK. Prevalence of gastrointestinal symptoms in pregnancy. Niger J Clin Pract. 2006;9:1-6.

2. Kuscu NK, Koyuncu F. Hyperemesis gravidarum: current concepts and management. Postgrad Med J.2002;78:76-9.

3. Koch KL. Gastrointestinal factors in nausea and vomiting of pregnancy. Am J Obstet Gynecol. 2002;186:198-203.

4. Richter JE. Gastroesophageal reflux disease during pregnancy. Gastroenterol Clin North Am. 2003;32:235-61.

5. Dowswell T, Neilson JP. Interventions for heartburn in pregnancy. Cochrane Database Syst Rev. 2008:CD007065.

6. Ponce J, Martinez B, Fernandez A, Ponce M, Bastida G, Pla E, et al. Constipation during pregnancy: a longitudinal survey based on self-reported symptoms and the Rome II criteria. Eur J Gastroenterol Hepatol.2008;20:56-61.

7. Bradley CS, Kennedy CM, Turcea AM, Rao SS, Nygaard IE. Constipation in pregnancy: prevalence, symptoms, and risk factors. Obstet Gynecol. 2007;110:1351-7. 
8. Jewell DJ, Young G. Interventions for treating constipation in pregnancy. Cochrane Database Syst Rev. 2001:CD001142.

9. Koch KL, Frissora CL. Nausea and vomiting during pregnancy. Gastroenterol Clin North Am. 2003;32:201-34.

10. Keller J, Frederking D, Layer P. The spectrum and treatment of gastrointestinal disorders during pregnancy. Nat Clin Pract Gastroenterol Hepatol. 2008;5:430-43.

11. Lacasse A, Rey E, Ferreira E, Morin C, Berard A. Epidemiology of nausea and vomiting of pregnancy: prevalence, severity, determinants, and the importance of race/ethnicity. BMC Pregnancy Childbirth.2009;9:26.

12. Wald A. Constipation, diarrhea, and symptomatic hemorrhoids during pregnancy. Gastroenterol Clin North Am.200;32:309-22.

13. Goodwin TM. Nausea and vomiting of pregnancy: an obstetric syndrome. Am J Obstet Gynecol. 2002;186:184-9.

14. Lagiou P, Tamimi R, Mucci LA, Trichopoulos D, Adami HO, Hsieh CC. Nausea and vomiting in pregnancy in relation to prolactin, estrogens, and progesterone: a prospective study. Obstet Gynecol. 2003;101:639-44.

15. Richter JE. Heartburn, Nausea, Vomiting During Pregnancy. Pregnancy in Gastrointestinal Disorders. 2 Ed: American College of Gastroenterology 2007. p.18-25.

16. Miller JP. Inflammatory bowel disease in pregnancy: a review. J R Soc Med. 1986;79:221-5.

17. Chou FH, Lin LL, Cooney AT, Walker LO, Riggs MW. Psychosocial factors related to nausea, vomiting, and fatigue in early pregnancy. J Nurs Scholarsh. 2003;35:119-25.

18. Swallow BL, Lindow SW, Masson EA, Hay DM. Psychological health in early pregnancy: relationship with nausea and vomiting. J Obstet Gynaecol. 2004;24:28-32.

19. Einarson A, Maltepe C, Boskovic R, Koren G. Treatment of nausea and vomiting in pregnancy: an updated algorithm. Can Fam Physician. 2007;53:2109-11.

20. Broussard CN, Richter JE. Nausea and vomiting of pregnancy. Gastroenterol Clin North Am. 1998;27:123-51.

21. Bulik CM, Sullivan PF, Fear JL, Pickering A, Dawn A, McCullin M. Fertility and reproduction in women with anorexia nervosa: a controlled study. J Clin Psychiatry. 1999;60:130-5.

22. Waugh E, Bulik CM. Offspring of women with eating disorders. Int J Eat Disord. 1999;25:123-33.

23. Freeman JJ, Altieri RH, Baptiste HJ, Kuo T, Crittenden S, Fogarty $\mathrm{K}$, et al. Evaluation and management of sialorrhea of pregnancy with concomitant hyperemesis. J Natl Med Assoc. 1994;86:704-8.

24. Naveen S, Asha ML, Shubha G, Bajoria AA, Jose AA. Salivary Flow Rate, $\mathrm{pH}$ and Buffering Capacity in Pregnant and Non-Pregnant Women - A Comparative Study. JMED Research. 2014;2014:1-8.

25. Bassey OO. Pregnancy heartburn in Nigerians and Caucasians with theories about aetiology based on manometric recordings from the oesophagus and stomach. Br J Obstet Gynaecol. 1977;84:439-43.

26. Christie JA, Rose S. Constipation, Diarrhea, Hemorrhoids and Fecal Incontinence. Pregnancy in Gastrointestinal Disorders. 2 Ed: American College of Gastroenterology; 2007.p. 4-9.

27. Yallew WW, Terefe MW, Herchline TE, Sharma HR, Bitew BD, Kifle MW, et al. Assessment of water, sanitation, and hygiene practice and associated factors among people living with HIV/AIDS home based care services in Gondar city, Ethiopia. BMC Public Health.2012;12:1-10

28. Rakusan K. Drugs in pregnancy: Implications for a cardiologist. Exp Clin Cardiol. 2010;15:100-3.

Cite this article as: Jemilohun AC, Fasanu AO, Tijani AM, Stanley OG. Prevalence of gastrointestinal symptoms and related drug use among pregnant women of South-Western Nigeria. Int J Reprod Contracept Obstet Gynecol 2015;4:1464-70. 